\title{
Liver Collagen Synthesis in Murine Schistosomiasis
}

\author{
Michael A. Dunn, Marcos Rojkind, Kenneth S. Warren, Penelope K. Hait, \\ LEONARD RifAS, and SAM SEIFTER
}

From the Liver Research Center, Departments of Medicine and Biochemistry, Albert Einstein College of Medicine, Bronx, New York 10461, and the Division of Geographic Medicine, Department of Medicine, Case-Western Reserve University School of Medicine, Cleveland, Ohio 44106

A B S T RAC T Collagen synthesis was measured in liver slices obtained from mice with hepatosplenic schistosomiasis. Enlarged fibrotic livers from these mice contained 20 times more collagen than normal. This model of hepatic fibrosis results from an inflammatory granulomatous host response to Schistosoma mansoni ova in portal tracts, rather than from direct liver cell injury as with carbon tetrachloride-induced liver fibrosis. Collagen synthesis, as measured by the formation of labeled protein-bound hydroxyproline, occurred in granulomas isolated from fibrotic livers. Labeled collagen that cochromatographed with type I collagen was extracted with neutral salt solution from liver slices incubated with labeled proline. The free proline pool of the liver was doubled in infected mice; coordinately, liver slices from these animals showed maximal collagen production when the concentration of free proline in the medium was raised to $0.4 \mathrm{mM}$, the same level measured in the fibrotic livers. Under such conditions, collagen synthesis was at a rate equivalent to the formation of $5.4 \mathrm{nmol}$ of protein-bound hydroxyproline per $\mathrm{g}$ liver in $6 \mathrm{~h}$. In comparative incubations in medium containing 0.2 $\mathrm{mM}$ proline, fibrotic liver slices produced 16-fold more collagen than normal slices. The proline analogue, L-azetidine 2-carboxylic acid, effectively inhibited synthesis of labeled collagen by fibrotic liver slices. These studies show the synthesis of collagen in a reproducible animal model of the most prevalent form of human liver fibrosis. Definitition of the controlling factors in this system is of interest for the general problem of fibrosis produced by immunological responses.

This work was presented in part at the Annual Meeting of the American Federation for Clinical Research, Atlantic City, N. J., 30 April 1976. 1976. Clin. Res. 24: 283. (Abstr.)

Dr. Dunn is a U. S. Public Health Service Postdoctoral Research Fellow.

Received for publication 8 October 1976 and in revised form 6 December 1976.

\section{INTRODUCTION}

Hepatic fibrosis is marked by excessive deposition of newly synthesized liver collagen. Permanent distortion of architecture by fibrous tissue may dictate irreversibility in chronic liver diseases of diverse etiologies (1). Liver collagen deposition has been studied in detail in only one animal model system; the hepatic fibrosis produced in rats after chronic administration of carbon tetrachloride (2). In that model, as well as in human liver diseases, the metabolic events that stimulate liver collagen synthesis are unknown. In livers of humans with alcoholic cirrhosis and rats with $\mathrm{CCl}_{4}$-induced liver fibrosis, the pool of free proline, a major amino acid of collagen, was increased $(2,3)$. In the rat model system, the free proline pool of the liver was correlated with the rate of collagen synthesis measured in liver slices (2), and collagen synthesis was inhibited by administration of a proline analogue, L-azetidine 2carboxylic acid (4).

Hepatosplenic schistosomiasis, which afflicts more than 150 million persons infected with Schistosoma mansoni or Schistosoma japonicum, is the most prevalent form of hepatic fibrosis worldwide (5). Periportal fibrosis is the major disturbance during most of the course of this disease. Mice infected with $S$. mansoni cercariae provide an experimental model of liver collagen deposition whose course resembles that of the human disease $(6,7)$. In contrast to $\mathrm{CCl}_{4}$-induced liver fibrosis in rats, the hepatic fibrosis in schistosomiasis results from a cell-mediated immunological inflammatory host response (8), rather than from direct liver cell injury by a toxin.

The present study describes collagen synthesis by fibrotic liver slices from mice with hepatosplenic schistosomiasis. For this model, we report an increase in the pool of free proline and apparent dependence of net collagen synthesis on the concentration of free proline. The effect of the proline analogue, L-azetidine 2-carboxylic acid, was also studied. 

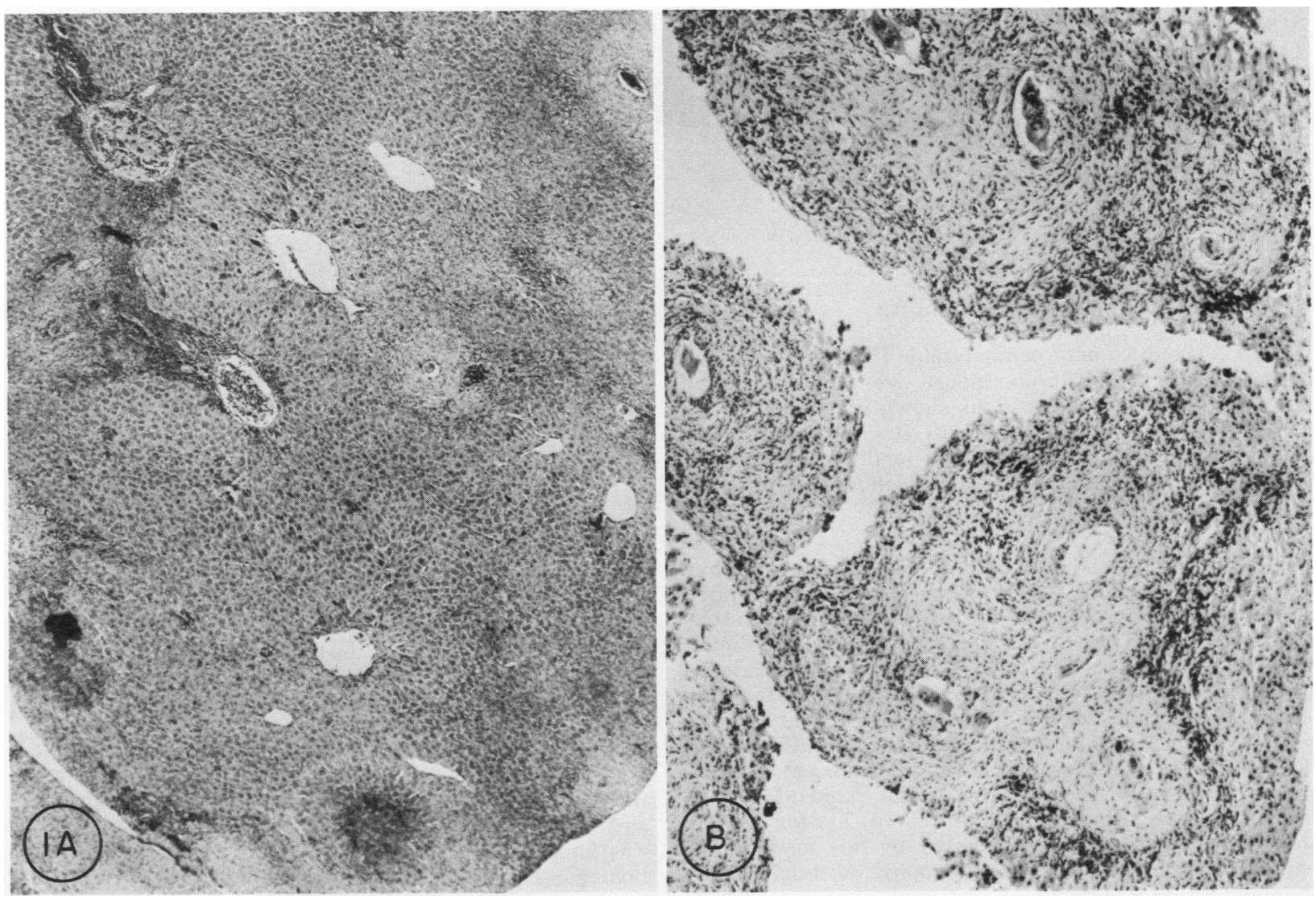

FIgure 1 (A) Liver from mouse 9 wk after subcutaneous injection of 50 cercaria of Schistosoma mansoni. Formation of granulomas in the portal tracts is evident with a pleomorphic cellular infiltrate and deposition of fibrous tissue (hematoxylin and eosin, original magnification $\times 40$ ). (B) Granulomas isolated from the liver of a 9-wk 50 cercariaeinfected mouse. Note relative paucity of intact hepatocytes, and preservation of granuloma morphology (hematoxylin and eosin, original magnification $\times 100$ ).

\section{METHODS}

Materials. Female CF1 mice weighing $20 \mathrm{~g}$ were obtained from Carworth Farms, New City, N. Y. Collagen was prepared from rat skin by extraction with $0.25 \mathrm{M}$ acetic acid, and dialysis against $0.02 \mathrm{M} \mathrm{Na}$ phosphate buffer $(9) . \mathrm{L}-\left[{ }^{3} \mathrm{H}\right]-$ proline, $2.5 \mathrm{Ci} / \mathrm{mmol}$, randomly labeled, and $\mathrm{L}-\left[{ }^{14} \mathrm{C}\right]$ proline, $0.26 \mathrm{Ci} / \mathrm{mmol}$, uniformly labeled, were obtained from Schwarz/Mann Div., Becton, Dickinson \& Co., Orangeburg, N. Y. L- $\left[{ }^{3} \mathrm{H}\right]$ Hydroxyproline, $2.5 \mathrm{Ci} / \mathrm{mmol}$, randomly labeled, and Aquasol were obtained from New England Nuclear, Boston, Mass. L-azetidine 2-carboxylic acid was obtained from Calbiochem, San Diego, Calif. L-Proline, Hepes buffer, and $\beta$-aminopropionitrile were obtained from Sigma Chemical Co., St. Louis, Mo. Earle's balanced salt solution (EBSS), ${ }^{1}$ penicillin, and streptomycin were obtained from Grand Island Biological Co., Grand Island, N. Y. Other reagents were of the highest purity available. Radioactive samples were counted in an SL 40 liquid scintillation counter from Teledyne Intertechnique, Westwood, N.J.

Preparation and incubation of liver slices. Mice were

${ }^{1}$ Abbreviation used in this paper: EBSS, Earle's balanced salt solution. injected subcutaneously with 50 cercariae of a Puerto Rican strain of Schistosoma mansoni (10). From 9 to $10 \mathrm{wk}$ later, livers were removed and rinsed in $0.14 \mathrm{M}$ chilled phosphatebuffered saline, pH 7.4. Thin slices, about $0.5 \mathrm{~mm}$, were made with a hand-held razor blade. Unless otherwise specified, slices for a given experiment were from one mouse liver.

200-mg wet wt, liver slices were incubated in $5 \mathrm{ml}$ EBSS containing $0.2 \mathrm{mM}$ L-proline, $25 \mathrm{mM}$ Hepes, $50 \mathrm{U} / \mathrm{ml}$ penicillin, and $50 \mu \mathrm{g} / \mathrm{ml}$ streptomycin. Unless otherwise specified, $100 \mu \mathrm{Ci} \mathrm{L}-\left[{ }^{3} \mathrm{H}\right]$ proline was added to each incubation flask. Incubation was done in 25-ml Erlenmeyer flasks under an atmosphere of $95 \% \mathrm{O}_{2}$ and $5 \% \mathrm{CO}_{2}$ in a shaking bath, 60 cycles $/ \mathrm{min}$, at $37^{\circ} \mathrm{C}$. Unless stated otherwise, reaction was stopped at $6 \mathrm{~h}$ by the addition of $5 \mathrm{ml}$ chilled absolute ethanol.

Measurement of labeled protein-bound hydroxyproline and proline. The ethanol-precipitated incubation mixtures were centrifuged at $27,000 \mathrm{~g}$ for $30 \mathrm{~min}$ at $4^{\circ} \mathrm{C}$. Supernates contained no labeled nondialyzable hydroxyproline. The precipitates were suspended in water and dialyzed exhaustively against running water. They were then placed in $6 \mathrm{~N}$ $\mathrm{HCl}$, sealed in ampules under vacuum, and hydrolyzed at $110^{\circ} \mathrm{C}$ for $18 \mathrm{~h}$. Hydrolyzates were filtered through glass wool, evaporated to dryness, kept overnight in a desiccator 


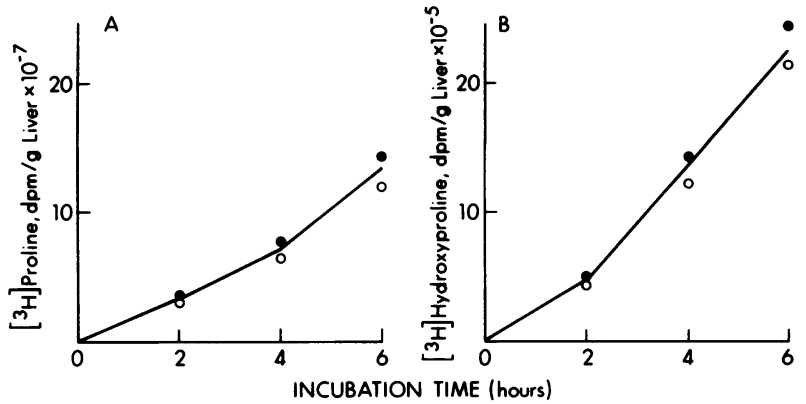

Figure 2 Production of nondialyzable $\left[{ }^{3} \mathrm{H}\right]$ proline $(\mathrm{A})$ and hydroxyproline (B) by fibrotic mouse liver slices incubated with $\left[{ }^{3} \mathrm{H}\right]$ proline. All incubations shown are from a single mouse liver. (O) Incubations with $0.5 \mathrm{mM} \mathrm{FeSO}{ }_{4}$ and $0.5 \mathrm{mM}$ ascorbic acid added to the medium; $(0)$ incubations without addition of these hydroxylation cofactors.

over $\mathrm{NaOH}$ flakes, and dissolved in $1 \mathrm{ml}$ of $0.2 \mathrm{~N}$ sodium citrate buffer, $\mathrm{pH} 2.75 .0 .5 \mathrm{ml}$ of the solution was applied to a C2 ion-exchange column $(0.6 \times 75 \mathrm{~cm})$ (Technicon Instruments Corp., Tarrytown, N. Y.) and eluted with a buffer gradient of increasing $\mathrm{pH}$ and ionic strenth (11) produced with a multiple-chamber reservoir as described by Piez and Morris (12). For the first $2 \mathrm{~h}$ of this process, $2.7-\mathrm{ml}$ fractions were collected at 3-min intervals and counted at $18 \%$ efficiency in $10 \mathrm{ml}$ of Aquasol. Elution positions of hydroxyproline and proline were verified with standard labeled amino acids. Radiochemical purity of hydroxyproline produced by liver slices and eluted by this method was confirmed by thin-layer chromatography, as described by Shen and Strecker (13).

Net collagen production by liver slices was expressed as nondialyzable labeled hydroxyproline, disintegrations per minute per gram liver, formed in $6 \mathrm{~h}$ of incubation.

Isolation of granulomas. Granulomas were prepared from 2.0-g pooled liver slices by brief homogenization using a loosefitting Dounce hand-held homogenizer (Kontes Co., Vineland, N. J.), in Hepes-buffered EBSS. Nearly all hepatocytes were disrupted and granulomas appeared morphologically normal (Fig. 1). Granulomas were sedimented and washed twice in EBSS. Granulomas isolated from $200 \mathrm{mg}$ of intact liver slices were incubated in the manner described above. After reaction was stopped by addition of ethanol, granulomas and medium were homogenized with a Teflon homogenizer and centrifuged at $27,000 \mathrm{~g}$ for $30 \mathrm{~min}$ at $4^{\circ} \mathrm{C}$. Supernates were evaporated to dryness, redissolved in water, and the specific activity of free proline was determined by the method of Rojkind and González (14). Precipitates were dialyzed against water, hydrolyzed, and labeled protein-bound hydroxyproline and proline were determined as described. The specific activity of proline was used to calculate collagen production as nanomoles of hydroxyproline formed during the incubation, and to calculate nanomoles of proline incorporated into total protein. These values were not corrected for the possible loss of tritium during proline hydroxylation.

Duplicate portions of isolated granulomas were hydrolyzed rather than incubated. Humin was removed from hydrolyzates as described by Prockop and Udenfriend (15), and total hydroxyproline was determined by the method of Rojkind and González (14). Other duplicate portions of granulomas were digested in 3\% $\mathrm{KOH}$ for schistosome egg counts as described by Cheever (16). Intact liver slices were also incubated, hydrolyzed, and digested under the same conditions.

Chromatography of labeled collagen. Extractable labeled collagen for chromatography was produced by incubation of liver slices with $\mathrm{L}-\left[{ }^{14} \mathrm{C}\right]$ proline, $20 \mu \mathrm{Ci} / 200 \mathrm{mg}$ liver, in 5 $\mathrm{ml}$ Hepes-buffered EBSS in the presence of $1.0 \mathrm{mM} \beta$ aminopropionitrile, an inhibitor of collagen cross-linking. After a 4-h incubation, $3 \mathrm{~g}$ of liver slices with $75 \mathrm{ml}$ medium was homogenized in a Teflon homogenizer and the suspension was stirred overnight at $4^{\circ} \mathrm{C}$. After centrifugation at $27,000 \mathrm{~g}$ for $30 \mathrm{~min}$ at $4^{\circ} \mathrm{C}$, the supernate was mixed with $10 \mathrm{mg}$ rat skin collagen in $15 \mathrm{ml} 0.05 \mathrm{M}$ Tris buffer, pH 7.4, containing $0.45 \mathrm{M} \mathrm{NaCl}$. The concentration of $\mathrm{NaCl}$ was adjusted to $3.42 \mathrm{M}$, and the mixture was centrifuged at $27,000 \mathrm{~g}$ for $30 \mathrm{~min}$ at $4^{\circ} \mathrm{C}$. The resulting precipitate was denatured at $60^{\circ} \mathrm{C}$ for $15 \mathrm{~min}$ in $15 \mathrm{ml}$ of $0.04 \mathrm{M}$ sodium acetate buffer, $\mathrm{pH} 4.8$, containing $1.0 \mathrm{M}$ urea. After centrifugation of the denatured material at $1,000 \mathrm{~g}$ for $5 \mathrm{~min}$ at $25^{\circ} \mathrm{C}$ the supernate was dialyzed against the same buffer, applied to a carboxymethylcellulose column $(0.9 \times 10 \mathrm{~cm})$, and eluted with the same buffer as described by Miller (17), with an added linear gradient of $\mathrm{NaCl}, 0-0.12 \mathrm{M}$. Absorption of the eluate was monitored at $230 \mathrm{~nm}, 3.5-\mathrm{ml}$ fractions were collected, and $0.5-\mathrm{ml}$ aliquots of the fractions were counted at $82 \%$ efficiency in $10 \mathrm{ml}$ Aquasol. Peak fractions were combined and dialyzed against distilled water; the solutions were then concentrated by evaporation, and hydrolyzed in $6 \mathrm{~N}$ $\mathrm{HCl}$. Labeled proline and hydroxyproline were determined chromatographically.

Comparative incubations of fibrotic and normal liver. The free proline pool was measured in the livers of five infected and five control mice. Animals were fed ad lib. and killed at 10 a.m. A 500-mg (wet wt) portion of liver was homogenized in $5 \mathrm{ml}$ cold $50 \%$ ethanol in a Teflon homogenizer. The supernate, obtained after centrifugation of the homogenate at $27,000 \mathrm{~g}$ for $30 \mathrm{~min}$ at $4^{\circ} \mathrm{C}$, was extracted with 2 vol of chloroform, and evaporated to dryness. The residue was dissolved in $2.0 \mathrm{ml}$ water, $\mathrm{pH}$ was adjusted to 6 , and proline was determined colorimetrically as described above (14).

The precipitates obtained by centrifugation of liver homogenates were resuspended and dialyzed against water. The dialyzed material was homogenized once more to a fine suspension, and duplicate aliquots were then taken for determination of protein nitrogen by a Kjeldahl method (18) and for colorimetric determination of hydroxyproline after acid hydrolysis as described above.

Liver slices from infected and normal mice were incubated in duplicate for each animal, at $0.2 \mathrm{mM}$ free proline in the medium. Synthesis of collagen and incorporation of proline into total protein were measured as described earlier.

Variation of concentration of proline and of a proline analogue. Liver slices were incubated in $0.05-0.80 \mathrm{mM}$ concentrations of free proline. Specific activity was maintained at a constant level by parallel increases in $\left[{ }^{3} \mathrm{H}\right]$ proline. Specific activity of proline in each incubation at $6 \mathrm{~h}$ was measured as described. A zero-time specific activity measurement was made in duplicate at $0.15 \mathrm{mM}$ proline concentration. In another experiment, liver slices were incubated in the presence of the proline analogue, L-azetidine 2carboxylic acid, at $1.0,10$, and $100 \mathrm{mM}$ concentrations.

\section{RESULTS}

Production of nondialyzable labeled proline and hydroxyproline by fibrotic liver slices is shown in Fig. 2 . There was a progressive rise in proline incorporated 
TABLE I

Comparison of Labeled Collagen Production by Intact Liver Slices and by the Granulomas Isolated from the Same Wet Weight of Liver Slices

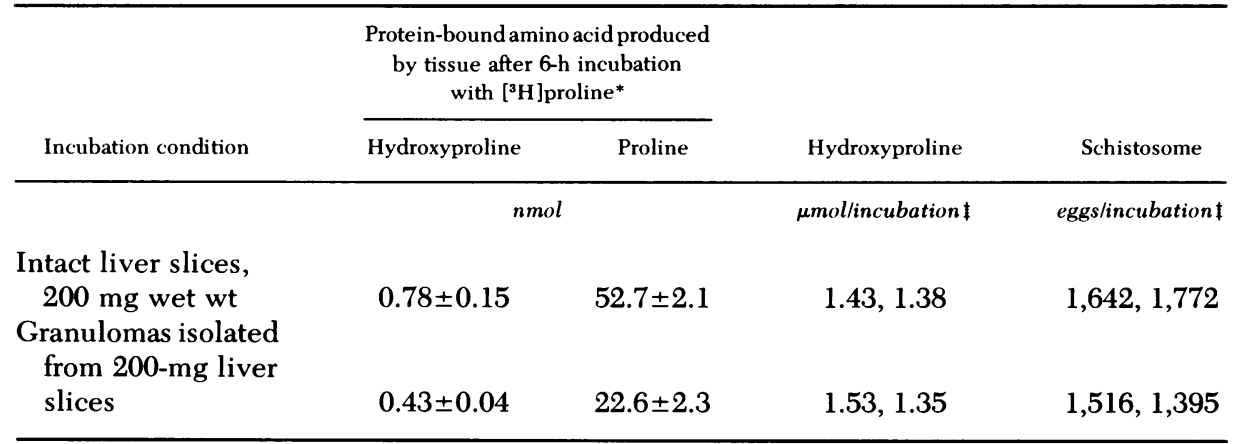

Production of protein-bound proline and recoveries of the collagen and schistosome eggs of the intact liver slices after the isolation procedure are shown.

* Mean ( \pm 1 SD) of four determinations.

$\ddagger$ Duplicate values reported.

into total liver protein over the 6-h incubation (Fig. 2A). About $1 \%$ of the labeled protein-bound proline was hydroxylated (Fig. 2B). Addition to the medium of hydroxylation cofactors, $0.5 \mathrm{mM}$ ferrous ion and 0.5 $\mathrm{mM}$ ascorbic acid, did not further enhance hydroxylation of proline residues. No protein-bound labeled proline or hydroxyproline was detected in liver slices incubated with $0.5 \mathrm{M} \mathrm{KCN}$. Use of enriched medium (basal medium Eagle) and addition of $10 \%$ dialyzed fetal calf serum did not increase the yield of labeled protein-bound proline or hydroxyproline (data not shown).

Production of collagen by isolated granulomas is shown in Table I. The isolation procedure gave $85 \%$ recovery of schistosome eggs and $100 \%$ recovery of collagen in the intact liver slices used as starting material. On incubation, granulomas isolated in this manner produced $55 \%$ of the amount of collagen produced by the intact liver slices from which they were separated. Isolated granulomas incorporated $43 \%$ as much proline into total protein compared with the liver slices.

After incubation of liver slices with $\left[{ }^{14} \mathrm{C}\right]$ proline and $1.0 \mathrm{mM} \beta$-amino-propionitrile, $19 \%$ of the total labeled hydroxyproline produced was extracted by stirring overnight in EBSS. Of this neutral-salt extractable labeled hydroxyproline, $30 \%$ coprecipitated with rat skin collagen and was chromatographed on carboxymethylcellulose (Fig. 3). The peak fractions of radioactivity that were eluted are shown in Table II, as well as the ratios of labeled hydroxyproline to proline in these fractions. The approximate 2:1 ratio of radioactivity that cochromatographed with rat skin $\alpha 1$ and $\alpha 2$ chains is consistent with the composition of type I rat skin collagen (9). The hydroxyproline: proline ratios of these peak fractions indicate normal hydroxylation of proline residues. Additional hydroxyproline radioactivity, designated peak fraction $\mathrm{D}$ in Table II, failed to chromatograph with type I rat skin collagen, and was eluted from the column with $0.05 \mathrm{~N} \mathrm{NaOH}$.

Free proline pools, shown in Table III, were increased twofold in fibrotic livers from infected mice as compared with normal mouse livers. Significance

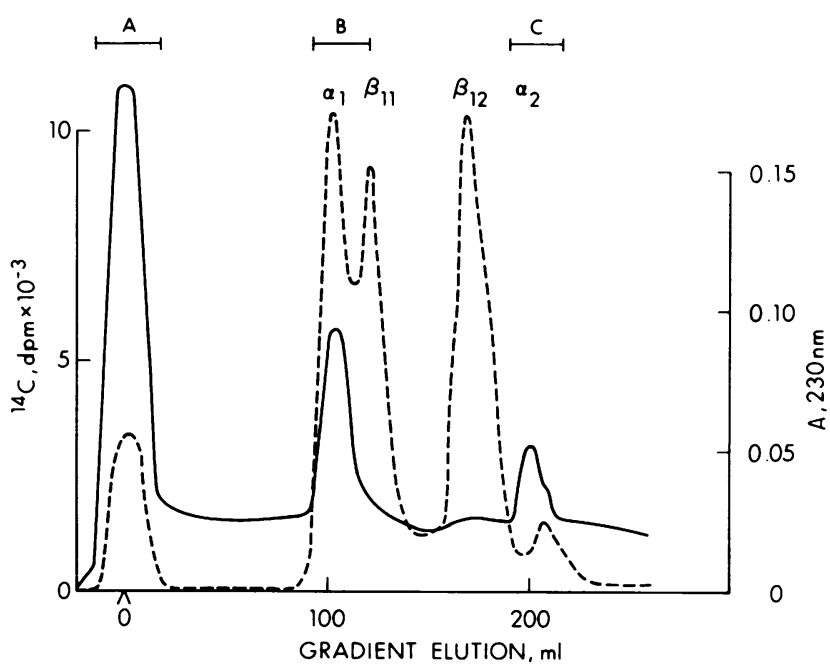

FIGURE 3 Chromatogram of labeled neutral-salt extractable collagen coprecipitating with rat skin collagen. After denaturation, material was eluted from carboxymethylcellulose with a salt gradient from 0 to $0.12 \mathrm{M}$ at $\mathrm{pH} 4.8$, in the presence of $1.0 \mathrm{M}$ urea. Absorbance at $230 \mathrm{~nm}$ is shown by the broken line and ${ }^{14} \mathrm{C}$ radioactivity is shown by the solid line. Known elution positions of type I rat skin collagen chains are marked $\alpha_{1}, \beta_{11}, \beta_{12}$, and $\alpha_{2}$. Material eluted in the exclusion volume (peak $A$ ), under peaks $B$ and $C$, and after washing the column with $0.05 \mathrm{~N} \mathrm{NaOH}$ (peak $\mathrm{D}$, not shown), was hydrolyzed (see Table II). 
TABLE II

Chromatographic Separation of Neutral-Salt Extractable Labeled Collagen Precipitating with Rat Skin Collagen

\begin{tabular}{|c|c|c|c|}
\hline & Peak & ${ }^{14} \mathrm{C}, \mathrm{dpm}$ & $\begin{array}{l}\left.{ }^{[14} \mathrm{C}\right] \text { hydroxypro- } \\
\text { line:proline }\end{array}$ \\
\hline (A) & Void volume & 37,100 & 0 \\
\hline & $\begin{array}{l}\text { Chromatographing with } \alpha_{1} \\
\text { chains }\end{array}$ & 18,000 & 0.62 \\
\hline (C) & $\begin{array}{l}\text { Chromatographing with } \alpha_{2} \\
\text { chains }\end{array}$ & 8,400 & 0.67 \\
\hline (D) & Eluted by $\mathrm{NaOH}$ & 74,500 & 0.12 \\
\hline
\end{tabular}

Peaks A, B, and C are marked in Fig. 3. Peak D was obtained by elution of the carboxymethylcellulose column with $0.05 \mathrm{~N} \mathrm{NaOH}$. The ratios of hydroxyproline to proline for $\alpha_{1}$ and $\alpha_{2}$ chains are consistent with normally hydroxylated type I collagen.

of all differences between means reported in Tables III and IV was determined by Fisher's $t$ test on unpaired data (19). Hydroxyproline content of infected livers, shown in Table IV, was increased 20-fold compared with normal livers, confirming the morphological evidence of increased liver collagen. The net synthesis of collagen by liver slices incubated with $\left[{ }^{3} \mathrm{H}\right]$ proline is also shown in Table IV. A 16-fold increase in liver collagen synthesis, as measured by formation of labeled nondialyzable hydroxyproline, was noted in fibrotic liver as compared with normal liver. Incorporation of proline into total protein was increased in the fibrotic livers compared with normal.

The relationship of net collagen synthesis by fibrotic liver slices to free proline concentration in the medium is shown in Fig. 4. Net synthesis of collagen by liver slices increased progressively at higher concentrations of free proline in the medium until a maximum of $5.4 \mathrm{nmol}$ hydroxyproline/g liver in $6 \mathrm{~h}$ was attained between 0.3 and $0.4 \mathrm{mM}$ free proline. A similar effect was observed for proline incorporated into total liver protein, with the same saturating maximum proline concentration (data not shown). Comparison of initial and final specific activities of proline in the medium showed a $16 \%$ decrease of radioactivity by $6 \mathrm{~h}$ at the $0.15-\mathrm{mM}$ proline concentration, with no change in the concentration of total proline measured in the medium.

The effect of L-azetidine 2-carboxylic acid on labeled collagen production is shown in Fig. 5. Formation of labeled protein-bound hydroxyproline decreased sharply as the concentration of the analogue in the medium was increased. At $100 \mathrm{mM}$ L-azetidine 2-carboxylic acid, production of labeled hydroxyproline was inhibited by $95 \%$. A parallel effect of the analogue was noted on incorporation of labeled proline into total liver protein (data not shown). Since transport of proline into protein-synthesizing compartments

TABLE III

Free Proline in Infected and Normal Mouse Liver

\begin{tabular}{ccccc}
\hline & & \multicolumn{3}{c}{ Free proline } \\
\cline { 3 - 5 } Mouse & Wet liver weight & $\mu$ mol/g Wet liver & $\mu$ mol/g Liver protein & $\mu$ molWhole liver \\
& $g$ & & & \\
Fibrotic & & & 3.09 & \\
1 & 2.49 & 0.312 & 2.58 & 0.777 \\
2 & 2.50 & 0.348 & 1.79 & 1.273 \\
3 & 3.12 & 0.408 & 2.65 & 1.262 \\
4 & 2.72 & 0.464 & 2.76 & 1.053 \\
5 & 2.46 & 0.428 & $2.57 \pm 0.48$ & $1.045 \pm 0.223$ \\
Mean* & $2.66 \pm 0.28$ & $0.392 \pm 0.061$ & & \\
& & & & 0.136 \\
Normal & & & 0.85 & 0.370 \\
1 & 0.97 & 0.140 & 1.39 & 0.358 \\
2 & 1.61 & 0.230 & 1.36 & 0.349 \\
3 & 1.59 & 0.225 & 1.22 & 0.360 \\
4 & 1.71 & 0.204 & 1.47 & $0.315 \pm 0.100$ \\
5 & 1.47 & 0.245 & $1.26 \pm 0.25$ & \\
Mean & $1.47 \pm 0.29$ & $0.209 \pm 0.041$ & & \\
\hline
\end{tabular}

Mice were killed at 10 a.m. with food available ad lib. Free amino acids were extracted by homogenization in cold $50 \%$ ethanol, and proline was determined colorimetrically. All differences between means of fibrotic and control groups were significant at $P<0.01$.

* Mean \pm 1 SD. 
TABLE IV

Collagen Content, Level of Infection, and Collagen Synthesis on Incubation of Fibrotic and Normal Mouse Livers

\begin{tabular}{|c|c|c|c|c|c|c|}
\hline \multirow[b]{2}{*}{ Mouse } & \multirow{2}{*}{$\begin{array}{c}\mu \mathrm{mol} / \mathrm{g} \\
\text { Wet liver }\end{array}$} & \multirow{2}{*}{$\begin{array}{c}\mu \mathrm{mol} / \mathrm{g} \\
\text { Liver protein }\end{array}$} & \multirow{2}{*}{$\begin{array}{c}\mu \mathrm{mol} / \\
\text { Whole liver }\end{array}$} & \multirow{2}{*}{$\begin{array}{l}\text { Schistosome eggs/ } \\
\text { g wet liver* }\end{array}$} & \multicolumn{2}{|c|}{$\begin{array}{l}\text { nmol Protein-bound amino acid } \\
\text { produced/g wet liver on } \\
\text { incubation for } 6 \mathrm{~h}\end{array}$} \\
\hline & & & & & Hydroxyproline* & Proline* \\
\hline \multicolumn{7}{|l|}{ Fibrotic } \\
\hline 1 & 8.74 & 86.53 & 21.76 & $4,965,3,985$ & $5.69,8.02$ & $279.3,335.2$ \\
\hline 2 & 7.56 & 56.00 & 18.90 & $5,515,5,535$ & $4.46,3.75$ & $258.7,261.8$ \\
\hline 3 & 12.10 & 53.07 & 37.75 & $5,045,4,190$ & $6.59,5.10$ & $340.2,281.3$ \\
\hline 4 & 14.29 & 81.66 & 38.87 & $5,170,5,105$ & $4.84,5.61$ & $185.4,214.5$ \\
\hline 5 & 12.10 & 78.06 & 29.77 & $4,430,3,760$ & $3.69,4.33$ & $188.2,208.6$ \\
\hline Mean $\ddagger$ & $10.96 \pm 2.75$ & $71.06 \pm 15.42$ & $29.41 \pm 4.05$ & $4,770 \pm 634$ & $5.20 \pm 1.33$ & $255.3 \pm 55.9$ \\
\hline \multicolumn{7}{|l|}{ Normal } \\
\hline 1 & 1.34 & 8.17 & 1.30 & - & $0.24,0.29$ & $176.4,155.9$ \\
\hline 2 & 0.84 & 5.09 & 1.35 & - & $0.33,0.32$ & $165.5,203.2$ \\
\hline 3 & 1.01 & 6.08 & 1.61 & - & $0.36,0.29$ & $163.1,164.1$ \\
\hline 4 & 1.18 & 7.07 & 2.02 & - & $0.32,0.33$ & $179.6,155.2$ \\
\hline 5 & 0.84 & 5.03 & 1.23 & - & $0.34,0.37$ & $122.6,135.6$ \\
\hline Mean $\ddagger$ & $1.04 \pm 0.22$ & $6.29 \pm 1.34$ & $1.50 \pm 0.32$ & & $0.32 \pm 0.04$ & $162.1 \pm 22.5$ \\
\hline
\end{tabular}

Liver slices were incubated for $6 \mathrm{~h}$ with $\left.{ }^{3} \mathrm{H}\right]$ proline at a concentration of $0.2 \mathrm{mM}$ proline in the medium. Collagen content expressed as hydroxyproline.

${ }^{*}$ Duplicate determinations reported. All differences between means of fibrotic and control groups significant at $P<0.01$.

$\ddagger$ Mean \pm 1 SD.

may be affected by this analogue (20), thus decreasing specific activity of proline available for protein synthesis, the data in Fig. 5 are reported in terms of radioactivity rather than protein synthesized.

\section{DISCUSSION}

Hepatic fibrosis in mice infected with Schistosoma mansoni results from a host response to soluble antigens secreted by living parasite eggs in portal venules (21): The early events of this reaction reflect a cellmediated immune response with production of lymphokines and formation of granulomas $(8,22)$. As in human schistosomiasis, primary liver cell injury is not an initiating event of this host reaction. This animal model permits study of collagen synthesis resulting from an initial immunologic stimulus, in contrast to the hepatic fibrosis produced in rats by chronic administration of carbon tetrachloride.

In fibrotic liver slices from mice infected with $S$. mansoni, collagen production was nearly linear over the 6-h incubation time studied. The granuloma isolation procedure gave a nearly quantitative recovery of the collagen and schistosome eggs present in intact liver slices, while maintaining over half the labeled collagen production of these slices. The decrease in collagen synthesis noted in isolated granulomas could have been produced by injury during the isolation procedure, or possibly by loss of collagen-synthesizing cells elsewhere in the liver. Preservation of much of the collagen synthesizing activity in granulomas is a first step in localization of this activity in fibrotic liver. Morphological studies of liver fibrosis suggest

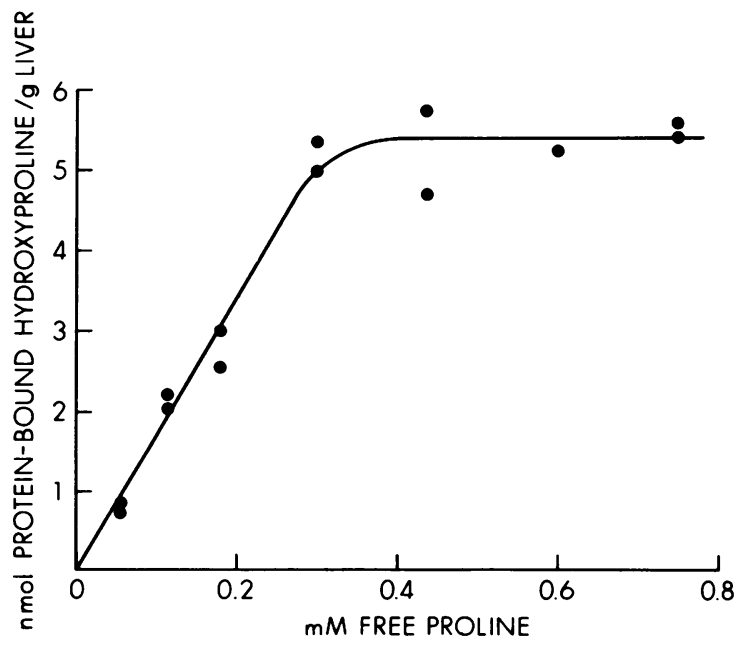

FIGURE 4 Production of collagen by fibrotic liver slices at increasing concentrations of free proline in the medium. 


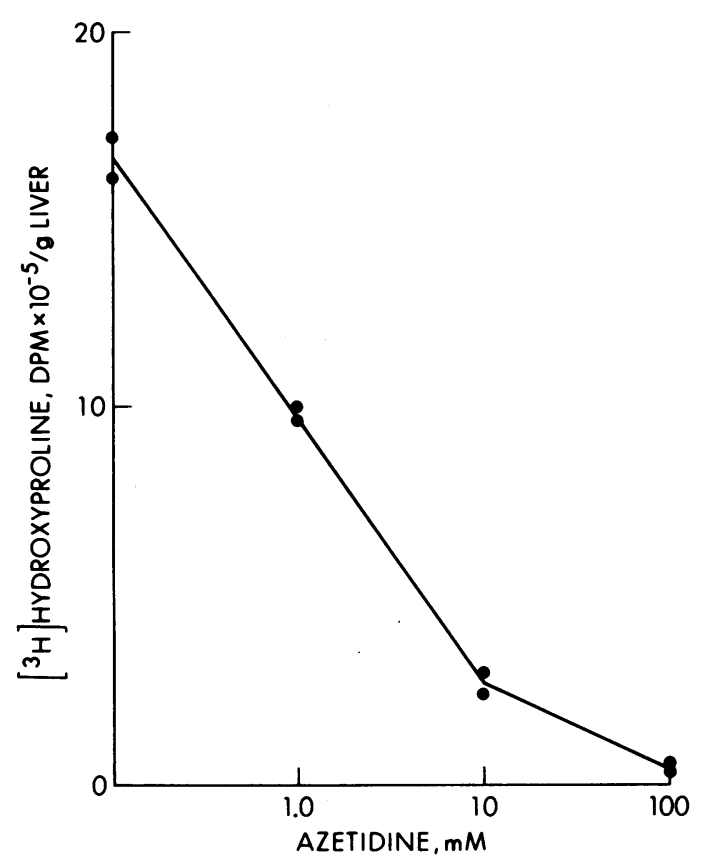

FIGURE 5 Labeled protein-bound hydroxyproline produced by fibrotic liver slices incubated with increasing concentrations of the proline analogue, L-azetidine 2-carboxylic acid.

that newly differentiated fibroblasts or littoral perisinusoidal cells synthesize collagen in response to liver injury $(1,23)$. In addition, a cell line derived from liver parenchymal cells has been shown to synthesize collagen (24). Our granuloma preparations did contain small numbers of adherent parenchymal cells so that the cell types that may produce collagen in murine schistosomiasis are not identified.

On incubation of fibrotic liver slices with the crosslinking inhibitor, $\beta$-aminopropionitrile, neutral-salt extractable collagen was produced that exhibited chromatographic properties consistent with type I collagen. The ratios of labeled hydroxyproline to proline in the peak fractions cochromatographing with rat skin $\alpha 1$ and $\alpha 2$ chains show that this collagen was normally hydroxylated. This finding is in agreement with the failure of added ferrous ion and ascorbate to produce higher yields of hydroxyproline. The bulk of labeled protein-bound hydroxyproline produced by liver slices was insoluble at physiologic $\mathrm{pH}$ and ionic strength. The $20 \%$ of total nondialyzable labeled hydroxyproline that was neutral-salt extractable but did not coprecipitate with carrier type I collagen might represent contributions of soluble collagen of other types, degraded small collagen peptides, the first component of complement (25), or possibly other hydroxyprolinecontaining peptides. Types I and III collagen are deposited in the livers of patients with alcoholic cirrhosis $(26,27)$. Perhaps more than one type of collagen is produced in schistosomiasis as well, and type I collagen may not be predominant. The complete characterization and quantitative proportions of collagen types produced must await extraction and analysis of all the hydroxyproline-containing protein.

Demonstration of an increased pool of free proline in the fibrotic livers of infected mice is similar to previous reports in studies of alcoholic cirrhosis in man and $\mathrm{CCl}_{4}$-induced liver fibrosis in rats $(2,3)$. Thus, the possibility that an elevated level of this key collagen constituent may be a constant abnormality in all cases of liver fibrosis is strengthened.

The source and intracellular location of the increased free proline pool is unknown. Increased hepatic sequestration of exogenous proline, increased synthesis of proline from the physiological precursors, arginine and glutamic acid (13), and decreased proline oxidation are potentially important mechanisms. In rats with carbon tetrachloride-induced liver fibrosis (2), and recently in rats with liver fibrosis after chronic ethanol administration (28), there was enhanced conversion of glutamic acid to proline. In shistosomiasis, parasite eggs may possibly synthesize proline, since adult worms may do so (29).

When the concentration of free proline in fibrotic liver slice incubations was increased, an increase in synthesis of collagen and of incorporation of proline into protein was noted, up to a saturating concentration of $0.4 \mathrm{mM}$ proline with respect to the medium. This saturating concentration in liver slice incubation mixtures is comparable with the free proline pool actually measured in the fibrotic livers. The data are consistent with the model proposed by Phang et al. (30) for saturable transport of proline into a collagensynthesizing compartment in fetal rat calvaria. The decreased proline specific activity noted in the medium after $6 \mathrm{~h}$ is consistent with equilibration of proline in the medium and in liver slices, and with possible synthesis of new unlabeled proline by the slices. The comparative incubations of fibrotic and normal liver slices were performed at a concentration of 0.2 $\mathrm{mM}$ free proline in the medium, equivalent to the free proline pool measured in normal liver. Thus, a marked increase in collagen synthesis by fibrotic liver was demonstrable at less than the apparent saturating maximum concentration of proline for fibrotic liver slices.

L-Azetidine 2-carboxylic acid exerts its major effect on the synthesis of proline-containing protein in cellfree systems by competitive inhibition of the acylation of tRNA with proline (31). As mentioned earlier, proline transport into cells may be blocked (20). In the case of collagen, an addtional effect has been suggested by evidence that procollagen chains containing residues of azetidine in place of proline are not well hydroxylated and thus susceptible to early degradation (32). In the fibrotic liver slices of this system, 
the predicted inhibition of collagen production did occur, in concert with a parallel decrease in proline incorporation into total protein.

These studies describe collagen synthesis of the most prevalent form of human liver fibrosis in a reproducible animal model. Comparative studies of the regulation of collagen production in this and other animal systems may define general control points, such as free proline levels, as potential targets for therapeutic intervention. Unlike other animal systems, the liver fibrosis in schistosomiasis results from a welldefined immunological stimulus. Thus, study of this system is also relevant to the general problem of immunologically stimulated fibrosis. Recently, Johnson and Ziff (33) have shown that a lymphokine-rich preparation from human mononuclear cells stimulated collagen synthesis by cultured human fibroblasts. Study of murine schistosomiasis may produce similar information on the mediators that link immunological activity to the pathway of collagen synthesis in hepatic fibrosis.

\section{ACKNOWLEDGMENTS}

We are indebted to the late Professor H. J. Strecker, and to Doctors I. M. Arias, S. Takahashi, and R. Lent for helpful suggestions and encouragement. The expert technical assistance of Mrs. L. Yuan Stiehl, Mr. P. A. Peters, and Mr. A. Davidson is acknowledged with appreciation.

This work was supported by the Edna McConnell Clark Foundation, U. S. Public Health Service Postdoctoral Fellowship F22 AIO1373 to Dr. Dunn, and National Institutes of Health grants AM17701, AI08163, and 1AG00374.

\section{REFERENCES}

1. Popper, H., and S. Udenfriend. 1970. Hepatic fibrosis. Correlation of biochemical and morphologic investigations. Am. J. Med. 49: 707-721.

2. Rojkind, M., and L. Diaz de León. 1970. Collagen biosynthesis in cirrhotic rat liver slices. A regulatory mechanism. Biochim. Biophys. Acta. 217: 512-522.

3. Kershenobich, D., F. J. Fierro, and M. Rojkind. 1970. The relationship between the free pool of proline and collagen content in human liver cirrhosis. J. Clin. Invest. 49: 2246-2249.

4. Rojkind, M. 1973. Inhibition of liver fibrosis by Lazetidine-2-carboxylic acid in rats treated with carbon tetrachloride. J. Clin. Invest. 52: 2451-2456.

5. Warren, K. S. 1973. Regulation of the prevalence and intensity of schistosomiasis in man: immunology or ecology? J. Infect. Dis. 127: 595-609.

6. Cameron, G. R., and N. C. Ganguly. 1964. An experimental study of the pathogenesis and reversibility of schistosomal hepatic fibrosis. J. Pathol. Bacteriol. 87: 217-237.

7. Warren, K. S. 1966. The pathogenesis of "clay-pipe stem cirrhosis". in mice with chronic schistosomiasis mansoni, with a note on the longevity of the schistosomes. Am. J. Pathol. 49: 477-489.

8. Warren, K. S., E. O. Domingo, and R. B. T. Cowan.
1967. Granuloma formation around schistosome eggs as a manifestation of delayed hypersensitivity. Am.J. Pathol. 51: 735-756.

9. Piez, K. A., E. A. Eigner, and M. S. Lewis. 1963. The chromatographic separation and amino acid composition of the subunits of several collagens. Biochemistry. 2: 58-66.

10. Peters, P. A., and K. S. Warren. 1969. A rapid method of infecting mice and other laboratory animals with Schistosoma mansoni: subcutaneous injection. J. Parasitol. 55: 558.

11. Autoanalyzer technical publication TAO-0155-10. 1973. Technicon Instruments Corp., Tarrytown, N. Y. Page D-O.

12. Piez, K. A., and L. Morris. 1960. A modified procedure for the automatic analysis of amino acids. Anal. Biochem. 1: $187-201$.

13. Shen, T.-F., and H. J. Strecker. 1975. Synthesis of proline and hydroxyproline in human lung (WI-38) fibroblasts. Biochem. J. 150: 453-461.

14. Rojkind, M., and E. González. 1974. An improved method for determining specific radioactivities of proline ${ }^{-14} \mathrm{C}$ and hydroxyproline $-{ }^{14} \mathrm{C}$ in collagen and in noncollagenous proteins. Anal. Biochem. 57: 1-7.

15. Prockop, D. J., and S. Udenfriend. 1960. A specific method for the analysis of hydroxyproline in tissues and urine. Anal. Biochem. 1:228-239.

16. Cheever, A. W. 1968. Conditions affecting the accuracy of potassium hydroxide digestion techniques for counting Schistosoma mansoni eggs in tissues. Bull. W. H.O. 39: $328-331$.

17. Miller, E. J. 1971. Isolation and characterization of a collagen from chick cartilage containing three identical $\alpha$ chains. Biochemistry. 10: 1652-1659.

18. Ma, T. S., and G. Zuazaga. 1942. Micro-Kjeldahl determination of nitrogen. A new indicator and an improved rapid method. Ind. Eng. Chem., Anal. Ed. 14: 280-282.

19. Fisher, R. A. 1958. Tests of significance of means, differences of means, and regression coefficients. In Statistical Methods for Research Workers. Hafner Press, New York. 13th edition, revised. 122- 127.

20. Finerman, G. A. M., S. Downing, and L. E. Rosenberg. 1967. Amino acid transport in bone. II. Regulation of collagen synthesis by perturbation of proline transport. Biochim. Biophys. Acta. 135: 1008-1015.

21. Boros, D. L., and K. S. Warren. 1970. Delayed hypersensitivity-type granuloma formation and dermal reaction induced and elicited by a soluble factor isolated from Schistosoma mansoni eggs. J. Exp. Med. 132: 488-507.

22. Boros, D. L., K. S. Warren, and R. P. Pelley. 1973. The secretion of migration inhibitory factor by intact schistosome egg granulomas maintained in vitro. Nature (Lond.). 246: 224-226.

23. McGee, J. O'D., and R. S. Patrick. 1972. The role of perisinusoidal cells in hepatic fibrogenesis. An electron microscopic study of acute carbon tetrachloride liver injury. Lab. Invest. 26: 429-440.

24. Sakakibara, K., M. Saito, M. Umeda, K. Enaka, and Y. Tsukada. 1976. Native collagen formation by liver parenchymal cells in culture. Nature (Lond.). 262: 316-318.

25. Reid, K. B. M., D. M. Lowe, and R. R. Porter. 1972. Isolation and characterization of Clq, a subcomponent of the first component of complement, from human and rabbit sera. Biochem. J. 130: 749-763.

26. Gay, S., P. P. Fietzek, K. Remberger, M. Eder, and K. Kuhn. 1975. Liver cirrhosis: immunofluorescence and biochemical studies demonstrate two types of collagen. Klin. Wochenschr. 53: 205-208.

27. Rojkind, M., and A. Martinez-Palomo. 1976. Increase 
in type I and type III collagens in human alcoholic liver cirrhosis. Proc. Natl. Acad. Sci. U. S. A. 73: 539-543.

28. Häkkinen, H. M., and E. Kulonen. 1975. Effect of ethanol on the metabolism of alanine, glutamic acid, and proline in rat liver. Biochem. Pharmacol. 24: 199-204.

29. Senft, A. W. 1963. Observations of amino acid metabolism of Schistosoma mansoni in a chemically defined medium. Ann. N. Y. Acad. Sci. 113: 272-288.

30. Phang, J. M., G. A. M. Finerman, B. Singh, L. E. Rosenberg, and M. Berman. 1971. Compartmental analysis of collagen synthesis in fetal rat calvaria. I. Perturbations of proline transport. Biochim. Biophys. Acta. 230: 146159.
31. Diaz de León, L. 1975. Regulación de la biosíntesis de colágena en la cirrosis experimental. Ph.D. thesis. Centro de Investigación y de Estudios Avanzados del Instituto Politécnico Nacional. Mexico City, 67-74.

32. Takeuchi, T., and D. J. Prockop. 1969. Biosynthesis of abnormal collagens with amino acid analogues. I. Incorporation of L-azetidne-2-carboxylic acid and cis-4fluoro-L-proline into protocollagen and collagen. Biochim. Biophys. Acta. 175: 142-155.

33. Johnson, R. L., and M. Ziff. 1976. Lymphokine stimulation of collagen accumulation. J. Clin. Invest. 58: 240252. 